\title{
Las raíces existencialistas del personalismo ontológico en la filosofía de Luigi Pareyson
}

\author{
Existentialist roots of ontological Personalism in Luigi \\ Pareyson's philosophy
}

\section{As raízes existencialistas do personalismo ontológico na filosofia de Luigi Pareyson}

Dra. Íris Fátima da Silva ${ }^{1}$

Trad. del Portugués por Dr. Luis Uribe Miranda²

Recibido: 04/08/2014 - Aceptado: 10/09/2014

\begin{abstract}
Resumen: El presente escrito se centra en la primera etapa del pensamiento de Luigi Pareyson. La tesis a demostrar es que el personalismo ontológico, como propuesta original del pensador italiano, hunde sus raíces en los estudios dedicados por Pareyson al existencialismo, como un pensamiento de la disolución del hegelismo. La insuficiencia de los conceptos de existencia y de síntesis dialéctica permitirá a Pareyson, a través de los conceptos de persona, libertad, singularidad, interpretación, auto y heterorrelación, articular una filosofía de cuño ontológico que renovará las investigaciones filosóficas de su época en Italia.
\end{abstract}

Palabras clave: Luigi Pareyson - Persona - Existencia - Personalismo ontológico - Autorrelación - Heterorelación.

1 Brasileña. Doctora en Filosofía por la Universidad Federal de Río Grande del Norte (UFRN), Natal, Brasil. Con pasantías de investigación en la Università degli Studi di Torino y la Università Cattolica del Sacro Cuore di Milano, en Italia y en la Pontificia Universidade Católica do Rio de Janeiro (Puc-Rio), en Brasil. Actualmente es Investigadora del Departamento de Artes de la Universidad Federal de Río Grande del Norte (UFRN), en Natal. Contacto: irisfsol@bol.com.br

2 NT. La presente traducción, tanto del portugués como del italiano, forma parte de la Investigación Postdoctoral en Filosofía que está realizando el traductor en la Universidad Federal de Minas Gerais (UFMG), Brasil. 


\begin{abstract}
The present paper focuses on the first stage of Luigi Pareyson's thought. The thesis to show is that the ontological Personalism as the original proposal by the Italian thinkerhas its roots in studies dedicated by Pareyson to Existentialism as a thought of the dissolution of Hegelianism. The insufficiency of the concepts of existence and dialectical synthesis allows Pareysonto articulate an ontological philosophy that renewed philosophical research of his time in Italy through the concepts of person, freedom, uniqueness, performance, auto and heterorelations.
\end{abstract}

Key words: Person- Existence - ontological Personalism - Autorelation - Heterorelation.

\title{
Resumo
}

O presente artigo centra-se na primeira fase do pensamento de Luigi Pareyson. A tese para demonstrar é que o personalismo ontológico, como proposta original do pensador italiano, tem suas raízes nos estudos dedicados por Pareyson ao existencialismo, como um pensamento da dissolução do hegelianismo. A inadequação dos conceitos de existência e de síntese dialética permitirão a Pareyson, através dos conceitos de pessoa, liberdade, singularidade, interpretação, auto e hetero- relação, articular uma filosofia de cunho ontológico que irá renovar as investigações filosóficas de sua época na Itália.

Palavras- chave: Pessoa - Existência - Personalismo Ontológico - Autorelação - Heterorelação.

\section{Introducción}

Luigi Pareyson investiga y reelabora, constantemente, los aspectos del fundamento de la temática existencialista, comprendidos como un camino del pensar que mejor interpreta y expresa los conflictos del hombre. En su filosofía es esencial e imprescindible tener conciencia de la singularidad de la persona y del principio en el que se coloca el pensar filosófico como una interpretación humana. Pareyson dedica una atención particular al concepto kierkegaardeano de coincidencia paradojal de autorrelación y heterorrelación en la singularidad de la existencia. Como sabemos, esos conceptos fueron interpretados de modo diferente por Karl Barth (1886-1968) y Martin Heidegger (1889-1976)3.

3 Cfr. FERRARIS, Maurizio. Storia dell'ermeneutica, Ed. Bompiani, Milán, 2008, pág. 43. 
El principio fundamental del mirar, personal y singular, debe estar inserto en el núcleo de cualquier filosofía. Pareyson valora la elección personal ampliándola al núcleo interpretativo inherente a la persona.

Para entender bien el significado del personalismo ontológico es necesario preguntar: ¿en qué consisten las fases constitutivas de la historia del pensamiento existencialista? ¿Por qué razón sólo permanecieron las perspectivas de los años 1919, 1927 y 1932? Estas fechas, en la mirada de Pareyson, nunca podrán ser olvidadas porque remiten a los títulos y autores de las principales obras destinadas a la comprensión de la filosofía de la existencia y, consecuentemente, de la persona y de la interpretación. El concepto de interpretación es pensado por Pareyson en el ámbito de la elección de la persona inherente a su singularidad y, por lo mismo, a la libertad. La interpretación se inserta al interior del conocimiento, sin embargo, es necesario recordar que el cognoscente es una persona.

La pregunta por el significado de la existencia y la tarea de la filosofía son pensadas por Pareyson en consonancia con la búsqueda de la comprensión de tres conceptos fundamentales: vida, persona y filosofía. La función de la filosofía es autónoma, especulativa4; la función de las relaciones entre vida, persona y filosofía es especular sobre el lugar de la persona en la vida y en la filosofía. En 1950, en Esistenza e persona, Pareyson retoma y desarrolla el personalismo ontológico, entendiendo la filosofía como teoría del hombre en el fundamento conceptual que dice: "La filosofía es obra del hombre y solamente del hombre. Es teoría del hombre hecha por el hombre para el hombre. Es pensamiento que no tiene otro objeto que el hombre, otro punto de vista que el humano, otro interlocutor que el hombre"

El presente escrito se centra en la primera etapa del pensamiento de Luigi Pareyson. La tesis a demostrar es que el personalismo ontológi-

4 Cfr. PAREYSON, Luigi. Interpretazione e storia, en Opere complete, Ed. Mursia, Vol. 14, Milán, 2007, pág. 5.

5 PAREYSON, Luigi. Esistenza e persona, (1950), Ed. Il melangolo, $5^{\text {a }}$ edición, Génova, 2002, pág. 215. 
co, como propuesta original del pensador italiano, hunde sus raíces en los estudios dedicados por Pareyson al existencialismo, como un pensamiento de la disolución del hegelismo, y que, por lo mismo, los conceptos pareysoneanos de persona, existencia, libertad, relación ontológica e interpretación poseen una fuerte deuda con ese pensamiento. A fin de demostrar nuestra tesis desarrollaremos este artículo en cinco apartados, mostrando los hitos fundamentales de las investigaciones de Pareyson.

\section{Un hito en la historia del existencialismo}

La primera de las tres fechas fundamentales de la historia del existencialismo, anunciadas anteriormente, es el año 1919. Su importancia reside en la coincidencia de que este hito acontezca al mismo tiempo que la publicación de dos obras de reconocida importancia. Por un lado, la Psicología de las visiones de mundo (Psychologie der Weltanschauungen) publicada en 1919 por Karl Jaspers (1883-1969), considerada como la primera obra de la filosofía de la existencia, cuyo argumento ya contiene los temas fundamentales desarrollados por Jaspers en trabajos posteriores. Por otro, la publicación, el mismo año, del comentario de Karl Barth a la Epístola a los romanos de San Pablo (Römerbrief); que será republicada en 1922. En esa publicación, siguiendo los comentarios de Reale y Antiseri, Karl Barth se posesiona contra la teología liberal reafirmando, no sólo la infinita distancia cualitativa entre el hombre y dios, sino que también la oposición substancial entre dios y todo aquello que es humano ${ }^{6}$, esto es, la razón, la filosofía y la cultura. Karl Barth quiere preservar la alteridad de dios, su ser totalmente otro ${ }^{7}$. Quiere poner las bases de la teología dialéctica o teología de la crisis que, como sabemos, influyó de sobremanera al mundo protestante alemán y francés.

En lo que se refiere a Jaspers, se considera la relevancia de su inquietud por la crisis del pensamiento y esa interrogación urgente que lo

6 Cfr. REALE, Giovanni et ANTISERI, Dario. História da filosofia: do Romantismo até nossos dias, Ed. Paulus, São Paulo, 2007, pág. 742.

7 Cfr. Ídem. 
llevó a la filosofía, remite a la pregunta por la razón que lo llevó a dedicar una extensa parte de su libro a Kierkegaard. En el lado aparentemente opuesto, es decir, en la teología de Karl Barth, se puede constatar el mismo interés por Kierkegaard. La idea de Pareyson, esencialmente, es que en la relación de Barth con Jaspers se hace patente el concepto de existencia como el ligamen que une las dos obras nombradas anteriormente, aunque en una primera mirada no sea tan perceptible. Más aún, de esta primera etapa de la historia del existencialismo se puede comprender el núcleo de la concepción existencialista de la filosofía. Sin embargo, para Pareyson, esa especulación filosófica, que pone el acento en la existencia, sería insuficiente y no podría anular el concepto de persona ${ }^{8}$. Es en este sentido que se comprende su diferencia con Karl Barth. De hecho, Pareyson publica en 1939 un texto titulado L'esistenzialismo di Karl Barth y que, diez años después, fue republicado en Studi sull'esistenzialismo. En aquel texto sobre el pensamiento bartheano, Pareyson plantea que "el pensamiento bartheano no quiere ser filosofía. Barth desconfía de la razón como una posibilidad puramente humana y que el hombre es radical negatividad" ${ }^{\prime \prime}$.

Es sabido, por otra parte, que en aquel tiempo Pareyson se refería, casi siempre, a Kierkegaard como un "agudo y atormentado teólogo"10; sin embargo, presenta y discute su pensamiento en dos de sus cursos universitarios en la Universidad de Turín. El primer curso dedicado a Kierkegaard fue el de 1964-1965 y el segundo, a su vez, en 19701971, respectivamente titulados: La ética de Kierkegaard en la primera fase de su pensamiento y La ética de Kierkegaard en la "Postilla", curso que, como dice Givone, contenía comentarios y notas al margen a fin de desarrollarlas ulteriormente ${ }^{11}$. En este período, el filósofo de

8 Cfr. PAREYSON, Luigi. Studi sull'esistenzialismo (1943), en Opere Complete, Ed. Mursia, Vol. 2, Milán, 2001, pág. 11.

9 Ibídem, pág. 127.

10 Ibídem, pág. 11.

11 Cfr. GIVONE, Sergio. "Premessa" a PAREYSON, Luigi. Kierkegaard e Pascal, en Opere complete, Ed. Mursia, Vol. 13, Milán, 1998, págs. 9-10. 
Turín estaba preparando los textos Verità e interpretazione, de 1971, y Esistenza e persona que tendrá diversas ediciones ${ }^{12}$.

En la perspectiva filosófica pareysoneana, la interpretación posee el lugar más coherente del existencialismo al ser comprendido como la disolución del hegelismo. Se concluye, en este sentido, que el hecho de que en el texto Esistenza e persona, presentado en la nueva edición, sostiene la tesis según la cual el existencialismo fue un nuevo modo de retomar la disolución del hegelismo. Esa temática, no por casualidad, fue enfrentada anteriormente por Feuerbach (1804-1872) y Kierkegaard en sus polémicas contra Hegel. Con todo, Pareyson refuerza la idea de que la disolución del racionalismo metafísico hegeliano exigía una alternativa. Entonces, ¿cuáles serían esas posibilidades? Dicha pregunta surge en la perspectiva pareysoneana de mostrar al existencialismo como constituyente y presupuesto de una filosofía de la interpretación cuyo origen se dio a través de la ya mencionada disolución del hegelismo.

Desde mi punto de vista, Pareyson plantea que tanto la imposibilidad de la objetividad, como la necesidad de la interpretación ya están contenidas en la primera fase del existencialismo y, por lo mismo, en el idealismo pre-hegeliano. Esto significa, siguiendo a Ferraris, afirmar que ambas cuestiones son tematizables al interior de una reactualización interpretativa del existencialismo como Personalismo Ontológico ${ }^{13}$. Pareyson aborda las diferencias de las dos visiones post-hegelianas, de Kierkegaard y Feuerbach, constatando que la interpretación de Kierkegaard está dirigida hacia el existencialismo, mientras que la de Feuerbach lo está para el marxismo y el actualismo. Kierkegaard disuelve el sistema hegeliano negando la identidad entre pensamiento y realidad, la reconciliación dialéctica entre historia y eternidad, anclando toda posible verdad en la subjetividad del individuo, incoercible a cualquier sistema absoluto del saber. Natu-

12 Cabe recordar que Esistenza e persona, publicado en 1950, tendrá cinco reediciones. Lo fundamental, es que en la reedición de 1985 Pareyson agrega el texto Le rettifiche sull'esistenzialismo, de 1975, porque le parece importante ver la discusión con el existencialismo como base de su personalismo ontológico.

13 Cfr. FERRARIS, Maurizio. Storia dell'ermeneutica, págs. 292-293. 
ralmente, Feuerbach, a ejemplo de Hegel, acepta la unidad entre el finito y el infinito reduciendo lo real a lo que es perceptible de modo sensible o deseable. Su crítica a Hegel se da, sobre todo, en el ámbito de las abstracciones hegelianas en nombre del hombre concreto, del individuo particular o de la política revolucionaria. Como afirman Reale y Antiseri, Feuerbach combatió, substancialmente, las abstracciones de Hegel en nombre de la concretud ${ }^{14}$. Sin embargo, como sabemos, para Pareyson la unidad de infinito y finito, historia y eternidad se realiza en el hombre. Me parece que Pareyson, una vez más, se colocaba frente a sus dilemas personales; es decir, a la cuestión de elegir si estar contra o a favor del cristianismo, como se constata en su obra póstuma, publicada en 1995, Ontologia deIla libertà. Il male e la sofferenza. Se puede afirmar que, quizás, era esperable que Pareyson optase por el aspecto trágico, dialéctico y paradójico del cristianismo.

No obstante lo anterior, tanto la ontologicidad del existencialismo, como su apertura a la trascendencia del ser y la comprensión de la existencia humana, conducen a Pareyson a interpretar su propio existencialismo dentro de la filosofía hermenéutica, cuya comprensión de la existencia es la comprensión del ser trascendente. Pareyson, como se puede constatar, se anticipó a los dos reconocidos filósofos hermenéuticos posteriores a Martin Heidegger, a saber, Hans-Georg Gadamer y Paul Ricoeur. Como sabemos, desde los inicios de los años 50, cuando los primeros escritos sobre su teoría de la interpretación ya estaban realizados, Pareyson ya había orientado su trabajo posterior a partir de sus escritos de la década precedente, centrándose en el problema de la unidad de la filosofía y de la multiplicidad de las filosofías ${ }^{15}$. En efecto, ésta será la cuestión que desembocará en su filosofía de la interpretación que, como sabemos, está desarrollada por primera vez en el texto de 1947, Il compito della filosofia oggi. Ahora, sin una preocupación puramente cronológica, se puede

14 Cfr. REALE, Giovanni et ANTISERI, Dario. História da filosofia: do Romantismo até nossos dias, pág. 174.

15 Cfr. Ídem. 
sostener con justicia que la hermenéutica de Pareyson es anterior a aquella desarrollada en Verdad y método por Gadamer en los años 60 y que, por lo mismo, el personalismo ontológico de Pareyson ya se nutría de su propia filosofía de la interpretación porque era en esa cuestión que se resolvía el problema de la disolución del hegelismo; es decir, la cuestión de la unidad y multiplicidad de la filosofía, como se podrá constatar en la gran introducción a su estudio sobre Fichte de 1950, donde plantea la insuficiencia de la crítica de la disolución del hegelismo, puesto que al privilegiar los conceptos de historicidad y excepcionalidad de la filosofía aún permanecen en un concepto de filosofía única. La propuesta de Pareyson consistirá en afirmar que la cuestión de la unidad y multiplicidad de la filosofía se consigue resolver a través de la incorporación de los conceptos de desarrollo autónomo, que replantea la cuestión de la historicidad de la filosofía en términos de condicionalidad histórica de la filosofía, y de interpretabilidad infinita, salvando tanto la unidad como la multiplicidad de la filosofía, y consiguiendo fundar una filosofía de la interpretación propia, capaz de asumir el riesgo constante del error, producto de ser una obra realizada por un ser humano, una persona ${ }^{16}$.

\section{El surgimiento de una nueva perspectiva}

El año 1927 puede ser considerado el segundo hito, o segunda etapa, en la historia del existencialismo. Dicho año es interpretado por Pareyson como un hito importante para el existencialismo por la publicación de dos libros: Ser y tiempo (Sein und Zeit) de Martin Heidegger y el Diario metafísico (Journal Métaphysique) de Gabriel Marcel. En 1927, según Pareyson, aún no se comprendía bien la relación entre Marcel y Heidegger, puesto que el primero era visto como un bergsoniano y el último como un fenomenólogo. En efecto, dice Pareyson, "el antiidealismo de Marcel aún parece, en el 27, un bergsonismo; sólo más tarde se nos lo explicará como existencialismo. Así en el 27 Heidegger es

16 Cfr. PAREYSON, Luigi. Fichte. Il sistema della libertà (1950), en Opere Complete, Ed. Mursia, Vol. 5, Milán, 2011, págs. 47-53. 
un fenomenólogo, pero hoy se sabe que es inadecuado el viejo esquema que lo colocaba en la línea de Husserl, Scheler y Heidegger. Del mismo modo, en el 27 es imposible una conexión entre Heidegger y Marcel; sólo ahora podemos encontrar un nexo, en base a un ontologismo común, según el cual el hombre está esencialmente ligado al ser. En la historia del existencialismo, junto a la revaloración del individuo, en consecuencia, se fija ahora el nuevo concepto de la ontologicidad del hombre"17. El existencialismo es ontológico, en la lectura de Pareyson, en base a los desarrollos de Heidegger y Marcel.

La pregunta por el sentido de ser, o la elaboración del problema del sentido del ser, contiene el despliegue de la comprensión propia del ser en cuanto existente. La cuestión es, entonces, ¿quién es el que se pregunta por el sentido del ser? La indicación será que es el hombre el ente privilegiado que se hace la pregunta por el sentido del ser que es él mismo. Sin embargo, esos cuestionamientos demuestran que el problema del sentido del ser en general exige la explicitación preliminar del ente que se plantea la pregunta sobre el sentido del ser. Considerado en su modo de ser, el hombre es precisamente Dasein, un ser-ahí o, mejor aún, una existencia. Esto, siguiendo a Giovanni Reale y Dario Antiseri, indica que el hombre está siempre en una situación, lanzado en ella y en relación activa con ella ${ }^{18}$. Estos cuestionamientos, sumados a la obstinada e incansable batalla contra el espíritu de abstracción, desarrolladas por Marcel, suscitarán muchas discusiones y cuestionamientos que, en la lectura de Pareyson, marcarán la segunda etapa de la historia del existencialismo; es decir, el giro ontológico de la existencia concreta.

\section{La importancia del existencialismo de Jaspers y Marcel}

La tercera fecha fundamental es 1932. Ese año fueron publicados los tres volúmenes del texto de Karl Jaspers Philosophie ${ }^{19}$. En ese mismo

17 PAREYSON, Luigi. Studi sull'esistenzialismo, págs. 11-12.

18 Cfr. REALE, Giovanni et ANTISERI, Dario. História da filosofia: do Romantismo até nossos dias, pág. 583.

19 El primer tomo se titulaba Orientación filosófica en el mundo, el segundo Clarificación de la existencia y el tercero Metafísica. 
año, se publica el primer fascículo de las Recherches philosophiques, donde aparece publicado el artículo de Gabriel Marcel sobre la filosofía de Jaspers. Esta tercera etapa es considerada por Pareyson como la más importante. Se puede decir que, entre los múltiples movimientos, aunque sean autónomos y separados, se inicia el lineamiento de una tendencia común, bien definida, instaurándose una conexión esencial. El libro de Jaspers constituye el apogeo del existencialismo alemán que, desde aquel momento, se mantuvo cerrado en la tríada Barth - Heidegger - Jaspers. Mientras que el existencialismo alemán se cerró, aislándose, se iniciaba la organización del tormentoso movimiento que, en esos últimos años, se denominó existencialismo francés.

Se infiere que el artículo de Gabriel Marcel apuntaba a mostrar diversos puntos de contactos, y también muchas diferencias, entre su propia filosofía y la de Karl Jaspers, como mostrarán los estudios existencialistas de Jean Walh ${ }^{20}$. Este filósofo estaba preocupado en realizar un filosofar más apegado a la experiencia en la diversidad de sus dimensiones. De acuerdo con Riconda, esta disposición asume la forma de un empirismo no reduccionista, que se desarrolla a través del reconocimiento de la complejidad, siempre presente en la experiencia "en la búsqueda de técnicas apropiadas para mantener el contacto vivo con ella y, a través de una conocida explicitación de ésas, que con cierta aproximación se podrían denominar las ineliminables características históricas y lingüísticas de la experiencia" ${ }^{21}$.

A este movimiento iniciado a partir de las Recherches philosophiques, se agregó en 1934 la corriente representada por la Filosofía del espíritu, cuyos mayores exponentes eran René Le Senne (1882-1954) y Louis Lavelle (1883-1951). De este modo se constituye un círculo de nombres en torno al movimiento Logos, dirigido por los ya men-

20 Cabe recordar que Jean Walh (1888-1974), discípulo de Henri Bergson, introdujo una relectura innovadora del pensamiento de Hegel en Francia, a partir del tema de la conciencia infeliz en los años treinta, mostrándose un defensor de Kierkegaard. 21 RICONDA, Giuseppe. "Ermeneutica dell'esperienza religiosa e ontologia", en Archivio di Filosofia, Vol. LXIV, N 1-3, Fasc. 63-64, Ed. Cedam, Padua, 1996, pág. 355. 
cionados Le Senne y Lavelle. Pero no sólo estos acontecimientos hacen del año 1932 un año importante, sino que también fijan un tercer carácter fundamental del pensamiento existencialista. No se puede olvidar que el artículo de Marcel acentúa y acepta la filosofía de Jaspers, sobre todo el concepto de situación fundamental, y se percibe cómo a los logros ya establecidos se agrega también un nuevo concepto de situación.

Se concluyen aquí, brevemente, las tres etapas de la historia del existencialismo. Es necesario enfatizar la importancia de la organización progresiva de las variadas tendencias, independientes pero convergentes, que denotan, también, un enriquecimiento progresivo del patrimonio especulativo existencialista; desde la revaloración del individuo heredada del pensamiento kierkegaardeano como una valoración encontrada y reconocida. Pareyson agrega una concepción ontológica cuya concepción del hombre es esencial a la unión originaria con el ser y con el concepto de situación.

No obstante lo anterior, para delimitar mejor los tres pilares del existencialismo de acuerdo con Pareyson, en la lectura de Riconda, se deben pensar cuatro cuestiones: la génesis y significado del existencialismo, la existencia como emergencia, la existencia como insistencia, la existencia como situación y ontologicidad ${ }^{22}$. Por lo mismo, para Pareyson, nos plantea Riconda, la "existencia no es sólo, etimológicamente hablando, exsistentia, ser fuera, emergencia, sino que también insistentia, ser dentro, presencia, intimidad; el individuo no se reduce al hecho de anularse en el ser, sino que se concretiza "insistiendo" en el hecho y asume significado participando del ser" 23. En el pensamiento de Pareyson no se puede reducir el existencialismo a filiaciones, derivaciones o deformaciones de un movimiento filosófico; al simple resumen de un autor o, menos aún, la rebelión contra una tendencia u otra.

22 Cfr. Ibídem, págs. 12-13.

23 Ibídem, pág. 16. 
Los existencialistas llegan de diversas partes y de distintas tendencias. Con todo, se encuentran o reencuentran en un terreno común; ¿se podría cuestionar si sería una tendencia del pensamiento contemporáneo? ${ }^{24}$

\section{Reacción a la dialéctica}

Desde mi punto de vista, la pregunta, que no tenía ninguna intención de callar, estaba dirigida al sentido de la existencia, sumada a la reivindicación de la inviolabilidad de la persona y la meditación sobre las ambigüedades, valores, confrontaciones y su historia. Este contexto se inserta en el principio fundamental de la síntesis articulada, realizada por Pareyson, entre el horizonte de su formación filosófica y las nuevas propuestas especulativas del inicio de los años cuarenta. No obstante esto, el existencialismo representa una reacción a la dialéctica y la implícita revaloración de todo aquello que no pueda ser reducido a la dialéctica. Desde el punto de vista de Pareyson, se deben destacar tres puntos existenciales: la singularidad, la trascendencia y la fractura.

El existencialismo, parafraseando a Pareyson, no es una mera revaloración del momento del individuo, sino más bien, la demostración de que el individuo no es, y no puede ser, un momento, sino que, más allá de eso, avanza resueltamente. Pareyson refuerza la idea según la cual, aunque la persona no pueda conseguir satisfacer enteramente la exigencia de la trascendencia, vista como la ultimidad que incide en aquella búsqueda, en la que lo buscado no puede reducirse en ningún caso, al final de cuentas acentúa y estimula la conciencia de la fractura, que está dialécticamente integrada, según el actualismo, en el proceso en el que se realiza el espíritu ${ }^{25}$.

Se requiere, por lo mismo, clarificar los conceptos de singularidad, trascendencia y fractura a partir del argumento entregado por el filósofo de

25 Cfr. PAREYSON, Luigi; Studi sull'esistenzialismo, pág. 198. 
Turín. El existencialismo, en la interpretación pareysoneana, presenta el concepto de singularidad del yo, pero al acentuar la irrepetibilidad y la infinitud vuelve a tomar los conceptos, puramente morales, de vocación y exigencia. Sin embargo, será a través del concepto de singularidad que se pueden constituir las bases para la profundización del concepto de persona. En efecto, como plantea Pareyson: "Esto es, que el existencialismo pone, con el concepto de singularidad, la base para una fructífera discusión del concepto de persona, pero no se preocupa, después, de desarrollar adecuadamente aquellas determinaciones morales que, por lo demás, están presentes en los despliegues de sus análisis y que, profundizadas oportunamente, pueden colocar en evidencia el concepto de valor, con el que solamente se puede fundar, filosóficamente, la persona" 26 .

En el planteamiento de Pareyson, el concepto de persona abandona los conceptos de individual y particular, pero acepta el concepto de singularidad porque, siguiendo a Riconda, la persona es tal solamente en su singularidad, en aquella concretud viva en la que, decidiendo por sí misma, es consciente de que se trata, verdaderamente, de la propia persona ${ }^{27}$. Ahora bien, en lo referente al concepto de trascendencia, y de acuerdo con Pareyson, el existencialismo es la revaloración de la trascendencia como irreductible a la dialéctica. La existencia es, esencialmente, relación, apertura y esfuerzo que tiende al ser. Como bien afirma Pareyson, "yo soy yo en cuanto tiendo al ser, que mi ipseidad no es, en el fondo, sino mi excentricidad, y que la esencia del hombre es la búsqueda. Lo que, todavía, vuelve a esto, que si el yo se realiza y se constituye como tal en su tendencialidad o intencionalidad, eso no es nunca naturaleza, estabilidad, estado, substancia, sino siempre acto, dinamicidad, esfuerzo, tendencia, búsqueda, y que la verdadera naturaleza del hombre es la historia, y que el hombre no es verdaderamente tal sino que, siempre, se hace tal y se conquista [...] el ser del hombre, que es un hacerse, es

26 Ibídem, pág. 200.

27 Cfr. RICONDA, Giuseppe. "Ermeneutica dell'esperienza religiosa e ontologia", pág. 202. 
tal en cuanto es un valer y un hacer valer y que la esencia del yo es búsqueda; no en cuanto la búsqueda sea naturaleza o destino del hombre, sino una constitutiva obligación interior del yo. De hecho, el yo no es inmediatamente búsqueda sino que, más propiamente, exigencia de búsqueda"28. Y continúa Pareyson: "ahora, está claro que la búsqueda es tal sólo si lo buscado está presente en la búsqueda pero sin resolverse en ella. Esta trascendencia de lo buscado no está siempre bien viva en la conciencia filosófica de algunos existencialistas; pero es claro que ese concepto es uno de los más relevantes de la doctrina y de la metafísica existencialista" ${ }^{29}$.

El concepto de búsqueda, según Pareyson, debe ser resuelto con los conceptos de exigencia e iniciativa de búsqueda, lo que no significa una trascendencia como punto final sino, como primer principio de la exigencia en sí misma, visto que el deber ser es tal sólo si fuere poder deber ser; el fundamento de la exigencia es la contingencia, en cuanto condición de la iniciativa, y es la posibilidad, es decir, la posibilidad de una conexión entre insuficiencia y obligatoriedad ${ }^{30}$. Francesco Paolo Ciglia interpreta el significado del existencialismo en la concepción de la existencia como una relación con el ser y luego, en la fundamentación de un concepto de trascendencia que, a su vez, no parece regirse si no fuere fundado en la esfera del valor ${ }^{31}$. El concepto de trascendencia no se resuelve con el acto, decía Pareyson, lo que equivaldría a reducirlo, sin un residuo, a pura inmanencia, mientras que, en tal esfuerzo de trascendencia, en el acto se valida la propia exigencia de trascendencia sólo si esta fuere acompañada de la conciencia del valor sostenido por el actualismo ${ }^{32}$, según Ciglia.

En relación al concepto de fractura, es necesario mostrar que se trata de un elemento importante. Siguiendo a Ciglia, el existencialismo se

\footnotetext{
28 PAREYSON, Luigi. Studi sull'esistenzialismo, págs. 202-203.

29 Ibídem, pág. 203.

30 Cfr. Ídem.

31 Cfr. CIGLIA, Francesco Paolo. Ermeneutica e libertà. L'itinerario filosofico di Luigi Pareyson, Ed. Bulzoni, Roma, 1995, pág. 35.

32 Cfr. Ídem.
} 
sirve de este elemento para acentuar la irreductibilidad de sí mismo a la dialéctica, contraponiéndolo a algunas temáticas y motivos de la tendencia del espíritu, cuya ética esencial del acto en la inactualidad del mal y su concepción de antivalor como contenido del juicio ${ }^{33}$. De este modo, el concepto de fractura contiene la aguda conciencia del antivalor, el sentido de la realidad del mal y la noción de incerteza de la decisión. Estos serán, para Pareyson, elementos constituyentes del concepto de angustia que, como sabemos, frecuentemente fue confundido por un sentimiento. A tal respecto, Pareyson afirma lo siguiente: "la angustia es el vértigo de la libertad, la conciencia del riesgo, el sentido agudo de la alternativa. En aquel punto, en el que decidimos nuestro destino, abandonados a nosotros mismos, librados de la amplitud de lo posible y completamente suspendidos en la vastedad de la nada, en aquella absoluta indeterminación totalmente dirigida hacia la resolución decisiva, en aquel instante de indecisión en el cual sabemos que eso que no optamos no lo podremos ser más e, incluso, nos embriagamos de la indiferencia, por la cual podemos ser cada una de las posibilidades no habiendo realizado todavía ninguna, en aquel punto, por tanto, nos ponemos a despedazarnos, como en una pérdida, con la que ponemos en peligro esa mismo inicio del cual esperamos muchos frutos" ${ }^{\prime \prime 3}$. Es en este sentido que, en la tercera parte del libro Studi sull'esistenzialismo, Pareyson afirmará que la angustia es el saber, la toma de conciencia, de que no se puede ejercitar la libertad sin comprometerla, porque ella es la esencia de la libertad, de conquistarse y después perderse, en el mismo acto en el que se afirma, de no poder siquiera ser mientras se pone en juego; por paradójico que pueda parecer, afirma Pareyson, "la libertad es libre de no ser libre, es como decir que ella es experiencia de la nada, iniciativa que pone la alternativa, indeterminación absoluta y dicotomía del obrar, pura exigencia que, en cuanto tal, también es pura posibilidad y, por lo mismo, también posibilidad negativa. He aquí el significado de aquello que, quizás metafóricamente, fue llamado por

33 Cfr. Ibídem, pág. 204.

34 PAREYSON, Luigi. Studi sull'esistenzialismo, pág. 204. 
el existencialismo angustia, riesgo, peligro, amenaza y todo aquello que la filosofía de la existencia contiene en su concepto de elección" $n^{\prime 35}$.

Sin embargo, aún se requiere inferir que en Pareyson la elección no es no poder elegir. En efecto, plantea Pareyson, "la elección no es no poder elegir, el acto no es una libre necesidad unívoca; la opcionalidad del acto como elección es, por el contrario, deber elegir, necesidad interior $y$, por lo mismo, contingencia, obligación y, en ella, posibilidad, deber que, tendiendo al sí para excluir al no, hace posibles tanto el no como el sí"36. El sentido existencialista de la fractura en Pareyson está, más aún, privado del carácter valorativo que puede darle sólo un significado; este carácter que se encuentra en el actualismo, y que, según Pareyson, Augusto Guzzo trató por muchos años, hablaba de la realidad y posibilidad del mal a fin de que haya una conciencia suficientemente viva de la elección y de las posibilidades del antivalor. Se trataba, según Pareyson, de enriquecer la fractura de la existencia con la axiología del juicio juzgador y de devolver al acto su carácter fundamentalmente opcional.

Se comprende de este modo, que la iniciativa es, al mismo tiempo, acto de invención y de juicio, mientras que, en la opción, ella es el fundamento de la alternativa. En verdad, como acto de juicio, la iniciativa es exigencia, llamado o vocación, y, después, contingencia, posibilidad y dicotomía, mientras que, como acto de invención, la iniciativa pone la alternativa. Francesco Tomatis lee ese planteamiento de Pareyson y afirma que el ámbito en el que la iniciativa se resuelve y elige, se concretiza, se singulariza y se define, porque la iniciativa elige la alternativa ${ }^{37}$.

En el texto Le rettifiche sull'esistenzialismo, Luigi Pareyson declara que fue la lectura realizada en 1936, en Alemania, del libro de Karl Jaspers, Vernunft und Existenz (Razón y existencia), publicado en 1935, la

35 Ídem.

36 Ídem.

37 Cfr. TOMATIS, Francesco. Pareyson. Vita, filosofia, bibliografia, Ed. Morcelliana, Brescia, 2003, pág. 60. 
que influyó en su opción por Kierkegaard. En la lectura de Pareyson, dicho libro es el núcleo del pensamiento de Jaspers, el anillo que une Philosophie, de 1932, con su obra más polémica, Von der Wahrheit (Sobre la verdad), de 1948. Esto provocará que la lectura pareysoneana de Heidegger fuese muy distinta a la de sus contemporáneos italianos (Graselli, Grassi, Mazzantini y Scaravelli), que siempre lo leían en conexión con Husserl, mientras que él lo hacía en conexión con Kierkegaard y, por lo mismo, con el existencialismo. En este sentido, dicha impronta kierkegaardeana, a la que aludíamos al comienzo de este artículo, aparece evidente. En efecto, escribe Pareyson, "leía a Heidegger muy consciente de su originalidad, porque las lecturas kierkegaardeanas que estaba realizando, me revelaban el auténtico significado (las primeras páginas de Enfermedad mortal ¿no son, quizás, el mejor comentario a la totalidad de la problemática del Dasein?) más que en el origen de la fenomenología" ${ }^{38}$.

Por otra parte, siguiendo a Negri, el existencialismo de Pareyson posee, desde siempre, una consonancia teórica con su filosofía de la interpretación o hermenéutica ${ }^{39}$. La interpretación para Pareyson, ya en los años cuarenta, presuponía algo para interpretar y un sujeto que interpreta. Recordemos que los primeros lineamentos de la teoría de interpretación están contenidos en los ya mencionados textos I/ compito della filosofia oggi, la introducción a Fichte. II sistema della libertà y, por último, Unità della filosofia de 195240; fundamentando la definición de la naturaleza del pensamiento filosófico y proponiendo un nuevo concepto de historiografía filosófica ${ }^{41}$. La elaboración teórica del referido concepto encuentra su núcleo en el texto Pensiero espressivo e pensiero rivelativo de 1965 y que después será usado por Pareyson

\footnotetext{
38 PAREYSON, Luigi. "Rettifiche sull'esistenzialismo", en Esistenza e persona, pág. 233.

39 Cfr. NEGRI, Antonio. "Luigi Pareyson esistenzialista ed ermeneuta", en COPPOLINO, Santo. Estetica ed ermeneutica di Luigi Pareyson, Ed. Cadmo, Roma, 1976, pág. 7.

40 Cfr. PAREYSON, Luigi. "Unità della filosofia", en Filosofia, № 4, Vol. 1, Turín, 1952, págs. 83-96. Después, al cuidado de Marco Ravera, será republicada por separado en el $N^{\circ} 1$ de Filosofia e teología, en 1995, págs. 65-79.

41 Cfr. PAREYSON, Luigi. Verità e interpretazione, (1971), en Opere complete, Opere Complete, Ed. Mursia, Vol. 15, Milán, 2005, págs. 238-239.
} 
como introducción a su libro Verità e interpretazione de $1971^{42}$. Se comprende así que Pareyson desarrolla su teoría de la interpretación a partir del argumento de que "no se puede poseer la verdad si no es en la forma de deberla buscar aún ${ }^{43}$. Se sigue de esto que la situación hermenéutica es, ante todo, una situación de búsqueda e investigación. La verdad debe ser concebida de modo crítico volviéndola admisible al hombre inmerso en la historia, lejos de la contemplación, vuelto hacia la pluralidad de perspectivas, empeñándose en no perderse en el relativismo.

\section{Conclusión}

En la perspectiva existencialista pareysoneana se encuentran, desde sus primeras investigaciones, la imposibilidad de la objetivación y la necesidad de la interpretación en el ámbito de una reactualización hermenéutica del existencialismo en vistas a un personalismo ontológico. De este modo, se puede comprender que, como afirma Ferraris, "entre el existencialismo y la interpretación existe, por tanto, una continuidad, no sólo en el sentido de que ambas delinean la parábola histórica de la disolución del hegelismo, sino que en cuanto ambas constituyen alternativas teóricas respecto a la sistemática hegeliana"44.

En su primer texto publicado en 1938, titulado Note sulla filosofia dell'esistenza $a^{45}$, Pareyson propone una confrontación crítica entre los pensamientos de Heidegger y Jaspers a partir de las relaciones entre la distinción heideggeriana de los términos alemanes existenzial y existenziell y la concepción de Jaspers de existenziell. La elección del argumento no fue casual, y menos el modo como fue

42 Cfr. Ibídem, págs. 15-31.

43 Ibídem, pág. 90.

44 FERRARIS, Maurizio. "Aspetti dell'ermeneutica del novecento", en II pensiero ermeneutico. Testi e materiali, Ed. Marietti, Génova, 1986, pág. 218.

45 Cfr. PAREYSON, Luigi. "Note sulla filosofia dell'esistenza", en Giornale critico della filosofia italiana, Fasc. 6, 1938, págs. 407-438. Este texto será republicado como "Esistenziale ed esistentivo nel pensiero di Martin Heidegger e Karl Jaspers" en Studi sull'esistenzialismo, págs. 141-173. 
desarrollado, que como sabemos manifiesta un interés que va bien más allá de las simples reconstrucciones filológico-historiográficas. Sobre estos términos, traducidos al italiano por Pareyson como esistenziale y esistentivo, se muestra, indistintamente, el carácter individualizante y la concretud de la existencia individual. En estos términos, Pareyson demuestra que la existencia es relación con el ser; es por esto que ella, al mismo tiempo que es relación con el ser, "es el ser del Dasein [...] Existencia significa, en el Dasein, autorrelación y relación con el ser, más aún, coincidencia de autorrelación y relación con el ser. La existencia, por esto, se presta a complicados análisis existenciales" ${ }^{\prime 4}$.

Sin embargo, es sabido que Pareyson dirigió su investigación teórica, acercándose más a la investigación existenciaria de Jaspers que a la analítica existencial de Heidegger y que, incluso, Heidegger fue leído a través de Jaspers. En otras palabras, que las investigaciones de Heidegger están volcadas a la existencia como estructura trascendental, en relación con el ser, mientras que Jaspers estaría volcado hacia una concretud singular. En efecto, plantea Pareyson, "si la filosofía de Heidegger es existencial, y dice relación a la estructura, la modalidad, la trascendentalidad de la existencia, el pensamiento de Jaspers es existenciario, porque apunta hacia la existencia en su concretud, singularidad e irrepetibilidad" ${ }^{\prime 4}$.

Se comprende aquí, una aparente aproximación a los términos usados tanto por Heidegger, como por Jaspers, para definir la existencia, simultáneamente e inseparablemente, como autorrelación, o mejor, coincidencia de autorrelación y heterorrelación, concepto que, como afirmábamos en párrafos anteriores, en la lectura de Pareyson, fue demostrado por Kierkegaard en las primeras páginas del texto de 1948, La enfermedad mortal. Esta relación es denominada por Pareyson como relación ontológica. Ciertamente que esta formulación, en términos de coincidencia dinámica, síntesis y pertenencia constitutiva de auto-

46 PAREYSON, Luigi. Studi sull'esistenzialismo, pág. 148.

47 Ibídem, pág. 141. 
rrelación y de heterorrelación con el ser se volverá un dato permanente en la historia del personalismo pareysoneano.

En este contexto, la coincidencia entre los dos términos, intentada por Heidegger, no parece satisfactoria porque, según Pareyson, se obtiene sacrificando la autorrelación en detrimento de la heterorrelación y, por otro lado, el intento de Jaspers tampoco tiene éxito, no obstante el énfasis en la autorrelación, ésta acaba perdiéndose en el inevitable naufragio. Esta doble insatisfacción se vuelve fecunda para Pareyson en su intento de encontrar justificaciones plausibles en relación a la problemática estudiada por ambos autores ${ }^{48}$ y su opción por repensar las cuestiones kierkegaardeanas. Esta idea se ve reforzada en el primer libro publicado por Pareyson en 1940, en el contexto del tratamiento del concepto de autorrelación y relación con lo otro (heterorrelación), al afirmar que "la existencia es, por tanto, la paradoja de la intimidad del individuo, ese punto interior en el que la relación consigo mismo coincide con la relación con Dios, donde alcanzo aquello que es más íntimo a mí mismo, que no yo a mí mismo" ${ }^{49}$.

En la interpretación de Riconda, que compartimos, el trayecto destinado al personalismo ontológico pareysoneano profundiza la coincidencia en la persona de autorrelación y heterorrelación, que Pareyson denomina relación ontológica, como fundamental para su nueva teoría de la interpretación con carácter personalista y ontológico ${ }^{50}$. En este sentido, se podría afirmar que la perspectiva filosófica pareysoneana, en su primera fase de desarrollo, está dedicada a poner las bases de la inseparabilidad de ser y libertad según la relación ontológica de la persona, considerando que toda relación humana tiene siempre un carácter interpretativo. Es necesario recordar aquí que Pareyson piensa el ser como libertad y, consecuentemente, afirma la caracte-

48 Cfr. Ibídem, págs. 170-173.

49 PAREYSON, Luigi. La filosofia dell'esistenza e Carlo Jaspers, Ed. Loffredo, Nápoles, 1940, pág. 8.

50 Cfr. RICONDA, Giuseppe. "Introduzione", en Pareyson. Persona e libertà, Ed. La scuola, Turín, 2011, pág. 15. 
rística ontológica de la libertad mostrando su cercanía y distancia del existencialismo.

Ciertamente que el personalismo ontológico u ontología de lo inagotable, término pareysoneano para indicar que la filosofía que propone es un personalismo, porque considera a la persona sujeto y objeto de la filosofía. Precisando aún más, un personalismo ontológico en el que la persona es mostrada por su propia esencia a través de la dimensión ontológica. La tesis fundamental del personalismo pareysoneano, siguiendo a Riconda, sostiene que la persona no puede relacionarse a sí misma sin relacionarse, al mismo tiempo, al ser, y el ser sólo es accesible a través de esta relación personal, sin que por esto el ser se reduzca a esta relación que instituye su propia posibilidad y que constituye su propio horizonte ${ }^{\prime \prime 51}$. Por consiguiente, la relación ontológica de la persona es esencialmente interpretativa; Pareyson se esfuerza siempre en mostrar el carácter interpretativo-ontológico de toda relación humana, como el núcleo de la filosofía personalista.

Durante este período Pareyson recalca sucesivamente tanto la actualidad de la disolución del hegelismo como la perspectiva del trayecto existencialista para el personalismo ontológico y destaca el significado que ellos asumen, al anticipar los desarrollos futuros, para una ontología de lo inagotable propuesta en Verità e interpretazione de 1971. El existencialismo comprendido como la filosofía que escucha las exigencias humanas, sobre todo en Pareyson, aumenta el componente personalista a la meditación como una experiencia original. Se percibe aquí, en el análisis pareysoneano, la ambigüedad de una confrontación que incita la polémica entre idealismo y existencialismo, denunciando las respectivas unilateralidades e intentando reivindicar el espacio estratégico de la hermenéutica en el ámbito del idealismo actualista y la nueva perspectiva oriunda del existencialismo europeo.

El análisis pareysoneano, todavía en esta primera fase, parece oscilar en un difícil, y no siempre claro, zigzag de convergencias y divergencias

51 Ibídem, pág. 8. 
entre una y otra perspectiva filosófica o entre instancias diferentes contenidas dentro de una misma perspectiva. Las evidentes divergencias en relación con Jaspers se acentuarán decisivamente a partir de 1948, ocasión en que el diálogo entre existencialismo y neoidealismo, al menos tal como fue concebido en los años precedentes, cuando Pareyson madura un nítido rechazo a las nuevas teorías jasperianas, las que interpreta como un retorno al hegelianismo ${ }^{52}$. Se concluye el presente texto, destacando que la osadía y riesgo de explorar en los años treinta y cuarenta y la propuesta especulativa sobre los conceptos de existencia y de persona, posibilitó a Pareyson dar una renovación a las investigaciones filosóficas en el circuito italiano, mostrando la importancia del personalismo ontológico.

\section{Bibliografía}

CIGLIA, Francesco Paolo. Ermeneutica e libertà. L'itinerario filosofico di Luigi Pareyson, Ed. Bulzoni, Roma, 1995.

FERRARIS, Maurizio. "Aspetti dell'ermeneutica del novecento", en II pensiero ermeneutico. Testi e materiali, Ed. Marietti, Génova, 1986.

Storia dell'ermeneutica, Ed. Bompiani, Milán, 2008.

GIVONE, Sergio. "Premessa" a PAREYSON, Luigi; Kierkegaard e Pascal, en Opere complete, Ed. Mursia, Vol. 13, Milán, 1998.

NEGRI, Antonio. "Luigi Pareyson esistenzialista ed ermeneuta", en COPPOLINO, Santo. Estetica ed ermeneutica di Luigi Pareyson, Ed. Cadmo, Roma, 1976, págs. 5-15.

PAREYSON, Luigi. "Note sulla filosofia dell'esistenza", en Giornale critico della filosofia italiana, Fasc. 6, 1938, págs. 407-438.

poles, 1940.

La filosofia dell'esistenza e Carlo Jaspers, Ed. Loffredo, Ná-

Studi sull'esistenzialismo (1943), en Opere Complete, Ed. Mursia, Vol. 2, Milán, 2001.

52 Cfr. CIGLIA, Francesco Paolo. Ermeneutica e libertà. L'itinerario filosofico di Luigi Pareyson, pág. 59. 
"Esistenziale ed esistentivo nel pensiero di Martin Heidegger e Karl Jaspers" en Studi sull'esistenzialismo, en Opere Complete, Ed. Mursia, Vol. 2, Milán, 2001, págs. 141-173.

14, Milán, 2007.

Interpretazione e storia, en Opere complete, Ed. Mursia, Vol.

Génova, 2002.

Esistenza e persona, (1950), Ed. II melangolo, $5^{\circ}$ edición, "Rettifiche sull'esistenzialismo", en Esistenza e persona, Ed. II melangolo, $5^{\circ}$ edición, Génova, 2002, págs. 231-252.

págs. 83-96.

"Unità della filosofia", en Filosofia, № 4, Vol. 1, Turín, 1952, Verità e interpretazione (1971), en Opere complete, Opere Complete, Ed. Mursia, Vol. 15, Milán, 2005.

Fichte. Il sistema della libertà (1950), en Opere Complete, Ed. Mursia, Vol. 5, Milán, 2011.

REALE, Giovanni et ANTISERI, Dario. História da filosofia: do Romantismo até nossos dias, Ed. Paulus, São Paulo, 2007.

RICONDA, Giuseppe. "Ermeneutica dell'esperienza religiosa e ontologia", en Archivio di Filosofia, Vol. LXIV, N 1-3, Fasc. 63-64, Ed. Cedam, Padua, 1996.

Turín, 2011. "Introduzione", en Pareyson. Persona e libertà, Ed. La scuola,

TOMATIS, Francesco. Pareyson. Vita, filosofia, bibliografia, Ed. Morcelliana, Brescia, 2003. 